\title{
Pre-Menstrual Training, Menstrual Hygiene Practices, Attitudes and Disorders among Nigerian Adolescents
}

\author{
Article by Afusat Adesina \\ Ph.D in Public Health, Texila American University, Nigeria \\ E-mail: afusatgain@gmail.com
}

\begin{abstract}
Objectives: Menstruation is a normal physiological process that begins during adolescence and may be associated with various symptoms occurring before or during the menstrual flow. Normal menstruation depends on a highly coordinated interaction between the hypothalamus, pituitary glands, ovaries and endometrium, with all events usually occurring in a cycle time frame often between 21 to 35 days. This study is therefore carried out to determine the influence of pre-menarcheal training on menstrual hygiene practices, the various menstrual disorders among the girls, as well as, the influence of educational status on menstrual hygiene practices, with a view to making necessary recommendations that would help improve such practices.

Methods: This cross sectional study was carried out in Lagos Nigeria. The target population was adolescent girls in this city. A multi-stage sampling technique was used to select the respondent. All data were statistically analysed, using statistical package for the social sciences (SPSS) and statistical test of significance was performed with Chi-Square test. Results: A total of 526 consenting respondents participated in the study with a mean age $\pm S D$ of $14.09 \pm 2.21$ years. Most of the respondents had their menarche (first menstruation) around 12 to 13 years of age, with the mean age \pm SD being $12.51 \pm 1.44$ years. 184 (35.0\%) experienced dysmenorrhoea (painful menstruation) during their last menstrual period and menorrhagia by 34 (6.5\%) of the respondent. Also, 142 (27.0\%) of the respondents have had a cycle $<21$ days or $>35$ days within their last three menstrual cycles.

Conclusion: Pre-menstrual training is common among these adolescent girls as it is evident in their menstrual hygiene practices. However, dysmenorrhoea and menorrhagia are common problems among adolescent girls thus health education \& health promotion are the best ways to deal with menstrual hygiene \& disorder issues effectively.
\end{abstract}

Keywords: Training, menstrual, hygiene, adolescent, Nigeria.

\section{Introduction}

Adolescence can be described as the transition period from childhood to adult use during which pubertal development and sexual maturation happen. In girls, it marks a special period signifying the transition from girlhood to womanhood. This period of transition is marked with the onset of menarche, which signifies a crucial landmark in girls' lifetime. During pubertal development, physical, hormonal, cognitive, psychological, among other changes occur simultaneously in such individual, with variations from person to person, due to several factors including genetic, environmental, nutritional, among other factors. Menstruation, a very crucial event in the reproductive life of women, is a normal physiological process that begins during adolescence and may be associated with various symptoms occurring before or during the menstrual flow [1]. Normal menstruation depends on a highly coordinated interaction between the hypothalamus, pituitary glands, ovaries and endometrium, with all events usually occurring in a cycle time frame often between 21 to 35 days. Menarche, which is the first menstruation period of life is a milestone that signifies maturation of reproductive potential and physiological growth and this normally happens at the age of 11 to 15 years most often and menopause, which is the end of woman's reproductive phase, most commonly occurring between the age of 45 to 55 years [2]. Although the physiology of menstruation and 
genital tract generally are taught in schools across Nigeria, the practical management of menstruation has often been seen as not appropriate for public discussion [3]. Menstrual disorders such as delayed menarche, dysmenorrhoea, pre-menstrual symptoms, among others, generally cause some apprehension among adolescents including their family members thus further justifying the reason to know the pattern of menstrual cycle, the training, practices and variations $[4,5]$.

A Nigerian research on the impact of pre-menarcheal training on menstrual practices andhygiene showed that the mean age was $14.9 y e a r s$ and $55.2 \%$ of the girls received premenarcheal training, with mothers (74.7\%) being the most common source of information [6]. In Eastern Sudan, some researchers reported that only $73 \%$ of the girls interviewed experienced menarche as at the time of the interview, with the mean age of 13.07 years, which was 0.9 years younger in the urban girls. The majority of the girls (76.4\%) experienced delayed menarche while $68.5 \%$ had regular period with cycle length ranging between 21 to 35 days. They also reported $83.1 \%$ dysmenorrhoea and 59.8\% pre-menstrual symptoms [7]. A 2012 research outcome in India revealed that abnormal cycle length was common and affected $30.48 \%$ of the girls, with $56.15 \%$ dysmenorrhoea experience and $56.16 \%$ premenstrual syndrome reported. The mean ages for menarche were 13.51 and 13.67 years for urban and rural areas respectively [8]. In 2016, the authors of the cross-sectional study on menstrual disorders revealed that dysmenorrhoea was the most common menstrual disorder with 48.82\%, followed by abnormal cycle length (19.96\%) and menorrhagia (11.80\%) among girls whose average was 13.12 years [9]. Moreover, in Ethiopia, the authors of a study on menstrual pattern in the Northwest reported that, a normal cycle of 21 to 35 days was observed in $70.3 \%$ of the girls, mean duration of flow was 4 days with a range of 2 to 7 days, irregular cycles observed in $42.8 \%$ of the girls, $39.7 \%$ got information about menarche from their mothers, $26.6 \%$ from friends and $21.8 \%$ through teachers while the mean age was 16.9 years, the mean age at menarche was 15.8 years [10]. In Northern Nigeria, a 25.6\% premenstrual symptoms and $69.0 \%$ regular menstruation were reported among secondary school girls with mean age of 15.35 years while the mean menarche age was 12.53 years [11]. Authors of the Lebanese research on pattern of menstrual disorders reported $54.0 \%$ premenstrual syndrome, $43.8 \%$ irregular duration of menstruation and $38.1 \%$ dysmenorrhoea [12]. This study is therefore carried out to determine the influence of pre-menarcheal training on menstrual hygiene practices, the various menstrual disorders among the girls, as well as, the influence of educational status on menstrual hygiene practices, with a view to making necessary recommendations that would help improve such practices.

\section{Research hypothesis}

1) Educational status has no significant influence on menstrual hygiene practices

2) Relationship with mothers have no significant effect on pre-menarcheal training

3) Educational attainment of mother have no significant effect on pre-menarcheal training

\section{Materials and methods}

This cross sectional study was carried out in Lagos Nigeria. The target population was adolescent girls in this city. A semi-structured questionnaire was administered consecutively on 526 respondents. Demographic and socio-economic information obtained were included. A multi-stage sampling technique was used to select the respondents from metropolis. In stage 1 from a sampling frame of the entire number of local government areas in Lagos State, one-third number of LGAs was selected using simple random sampling method. In stage 2, a list of towns in each of the selected LGA's was randomly made. In stage 3, houses in the towns were randomly selected. The final stage involved in the selection of consenting adolescent girls. The questionnaires were then administered on the respondents. 


\section{Sample size}

Sample size calculation was done using 95\% confidence interval, 0.05 precision and prevalence rate. Using prevalence of menstrual abnormalities of $45.6 \%$ in school girls by Adinma \& Adinma, 2008 [1]. With the use of Leslie Fischer's formula for population $>10,000$, the formula for sample size calculation is: $n=Z^{2} P Q / d^{2}[13]$.

$\mathrm{n}=\mathrm{Z}^{2} \mathrm{PQ} / \mathrm{d}^{2}$

Where:

$\mathrm{n}=$ minimum sample size, $\mathrm{d}=$ degree of precision (taken as 0.05 ),

$\mathrm{Z}=$ standard normal deviation at $95 \%$ confidence interval which is 1.96 ,

$\mathrm{P}=$ proportion of the target population (estimated at $22.2 \%$ which is $45.6 / 100=0.456$ ),

$\mathrm{Q}=$ alternate proportion (1-P) which is 1-0.456 $=0.544$

$\mathrm{n}=(1.96)^{2}(0.456)(0.544)=382$ $(0.05)^{2}$ 19

Also, adding a 5\% non-response rate, the minimum sample size (n) will be 5/100 X $382=$

Thus, it will be $19+382=401=n$

Statistical Analysis

Data was statistically analysed using Statistical Package for the Social Sciences (SPSS) for windows version 20.0 software (SPSS Inc., Chicago, IL, USA). All data were expressed as Mean \pm Standard Deviation (SD). Frequency counts were generated for all variables and statistical test of significance was performed with Chi-Square test. Significance was fixed P $<0.05$ and highly significance is $\mathrm{P}<0.01$.

\section{Results}

Socio-Demographic Data

A total of 526 consenting respondents participated in the study. The mean age \pm SD is14.09 \pm 2.21 years. Most of the respondents Christians, 316 (60.1\%) and are mainly in senior secondary school, 268 (51.0\%) followed by junior secondary school, 206 (39.2\%). The girls are mainly from a nuclear family background, 380 (72.2\%). The mothers' level of education were mainly diploma and first degree, 194 (36.9\%) followed by secondary school certificate holders, 74 (14.1\%).

Three hundred and thirty eight, which is equivalent to $64.3 \%$, of the respondents had premenstrual training, that is, information about menstrual cycle before first cycle, as they were told about and made to expect the first bleeding, with this done by mother, as reported by 258 respondents (49.1\%). Three hundred and thirty (62.7\%) of them were told how to collect menstrual blood, mainly informed that they should collect the blood into sanitary pads and $390(74.1 \%)$ were told how to dispose off the materials used to collect the menstrual period, with toilet/pit latrine, dust bin and burning listed as ways of disposal. Meanwhile, 432 (82.1\%) of the respondents currently use sanitary pad as the menstrual absorbent/material to collect their menstrual period. The primary source of information for menstruation is mainly through the mother, 322 (61.2\%). Menorrhagia, which is an abnormally heavy or prolonged bleeding, that is, the use of four or more fully soaked pads a day or bleeding more than 8 days, was said to have been experienced by $34(6.5 \%)$ of the respondent during the last menstrual period. Also, 142 (27.0\%) of the respondents have had a cycle $<21$ days or $>35$ days within their last three menstrual cycles.

In table 2, most of the respondents are reported to have had their menarche (first menstruation) around 12 to 13 years of age, with the mean age \pm SD being $12.51 \pm 1.44$ years. Most of them reported the first menstruation experience to be frightening, 170 (32.3\%). With last menstrual blood flow duration being reported mostly as 4 and 5 days, the mean \pm SD of blood flow duration is $4.40 \pm 1.14$ days. Regarding the amount of the last menstrual blood flow, most of the respondents reportedly used 2 pads per day. One hundred and eighty four (35.0\%) experienced dysmenorrhoea (painful menstruation) during their last menstrual period, with 124 (23.6) reportedly using drugs during the course of the pain chiefly pain 
Texila International Journal of Public Health

Volume 4, Issue 4, Dec 2016

killers or analgesics such as acetaminophen and non-steroidal anti-inflammatory drugs (NSAIDs) and prescribed by their mothers in most of the cases.

\section{Discussion}

This research outcome has shown that most of the respondents are in the range of 11 to 16 years, with the mean age \pm SD being $14.09 \pm 2.21$ years. This is very similar to other research outcomes which showed their mean age to be in this range $[6,9,10,11]$. Three hundred and thirty eight, which is equivalent to $64.3 \%$, of the respondents had pre-menstrual training, that is, information about menstrual cycle before first cycle, as they were told about and made to expect the first bleeding, with this done by mother. This is comparable to the outcome of another research which reported that $55.2 \%$ of the respondents received pre-menarcheal training and perhaps mainly through their mothers [6]. In this study, pre-menarcheal training was found to be significantly associated with the educational attainment of the respondents' mothers, thus influencing the probable information passed on to the girls. 432 (82.1\%) of the respondents currently use sanitary pad as the menstrual absorbent/material to collect their menstrual period. This is not strange owing the fact the pads are readily available and affordable, perhaps most girls believe the pads help prevent genital infections. However, with most of the information on pre-menstrual training and training obtained from the mother and not elsewhere especially places health workers or hospital or even in the school through teachers show that organized health information and education is highly required for adolescents as they complement family life education learned from home, thus in the process will serve to correct the wrongly passed information and enhance correct peer health education propagation.

One hundred and eighty four (35.0\%) experienced dysmenorrhoea (painful menstruation) during their last menstrual period. This is not in agreement with other studies that have shown far higher proportions, as 83.1\% dysmenorrhoea was reported in Eastern Sudan [7], 56.15\% dysmenorrhoea in India [8] but similar to other studies including the $38.1 \%$ dysmenorrhoea reported in Lebanon [12] and 48.82\% respondents in India. The painful menstruation was reportedly said to have hampered certain part of the respondent's social life or even schooling activities, especially with menstrual symptoms mainly including backache, headache, fatigue and mood swing complicating the issue, as the menstrual symptoms form part of regular women cycle largely because dysmenorrhoea begins around the time menstruation begins, with the pain often around the pelvis or lower abdomen. Furthermore, $142(27.0 \%)$ of the respondents have had a cycle $<21$ days or $>35$ days within their last three menstrual cycles. The outcome is in agreement with the Eastern Sudan and Ethiopian studies which showed $68.5 \%$ and $70.3 \%$ respondents respectively had regular period with cycle length ranging between 21 to 35 days [7, 10]. This can be considered a regular event especially as ovulation is said to occur in the first two years after menarche [14]. Pre-menstrual symptoms are found to be very common among these adolescents with mood changes, breast tenderness, generalized fatigue, among others, which is in agreement with other studies; 59.8\% premenstrual symptoms in Sudan [7], 56.16\% pre-menstrual syndrome in India [8] and 25.6\% pre-menstrual symptoms in Northern Nigeria [11].

Most of the respondents had their menarche (first menstruation) around 12 to 13 years of age, with the mean age \pm SD being $12.51 \pm 1.44$ years. This is in contrast to the Sudanese research outcome which reported $76.4 \%$ delayed menarche [7], as well as the mean age at menarche reported as 15.8 years in Ethiopia [10], but similar to the outcome of the study in Northern Nigeria where the mean menarche age of 12.53 years was reported [11] and in India, where the mean ages for menarche were 13.51 and 13.67 years for urban and rural areas respectively [8]. This shows that generally girls experience menarche at different ages, the timing of which is influenced by the female biology coupled with environmental factors especially nutrition as well as genetics.

The acceptance of the first hypothesis on educational status on menstrual hygiene practices shows that education doesn't necessarily determine the menstrual hygiene practices. Also, the 
acceptance of the second hypothesis on the relation with mothers on pre-menarcheal training shows that the training is not dependent on the closeness of the adolescent girl with the mother. Meanwhile, the rejection of the third hypothesis on educational attainment of mother having no significant effect on pre-menarcheal training shows that the education of the mothers determine the possible information that would be stepped down to the young girls as this is evident in the fact that most of the mothers have got diploma and first degree qualifications.

\section{Conclusion}

Pre-menstrual training is common among these adolescent girls as it is evident in their menstrual hygiene practices. However, dysmenorrhoea and menorrhagia are common problems among adolescent girls thus health education \& health promotion that include sexual and reproductive health are the best ways to deal with menstrual hygiene \& disorder issues effectively. It is therefore advised that these be included in the high school curriculum and implemented by teachers in order to enhance the teachings at home by the mothers of these young girls.

\section{References}

[1]. Adinma ED \& Adinma JI. Perceptions and practices on menstruation amongst Nigerian secondary school girls. Afr J Repro Health. 2008; 12: 74 - 83.

[2]. Adam HPJ. Menstruation in young girls: A clinical prospective. Obst Gynecol. 2002; 99 (4): 655 662.

[3]. Aniebue UU, Aniebue PN \& Nwankwo TO. The impact of pre-menarcheal training on menstrual practices and hygiene of Nigerian school girls. Pan Afr Med J. 2009; 2 (9): 1- 9.

[4]. Abdel Aziem AA, Duria AR, Mona M \& Ishag A. Age at menarche and menstrual cycle pattern among school girls in Kassala in Eastern Sudan. J Pub Health \& Epid. 2011; 3 (3): 111 - 114.

[5]. Adam HPJ. Menstruation in young girls. A clinical perspective. Obst. Gynecol. 2002; 99 (4): 655 662.

[6]. Daniel WW, Cross CL. Biostatistics: A foundation for analysis on health sciences, $10^{\text {th }}$ edn. New York, NY: Wiley, 2013.

[7]. Dutta DC. Textbook of gynaecology. $6^{\text {th }}$. Ed. New Delhi: Jaypee; 2015. p.82.

[8]. Diaz A, Laufer MR \& Breach L. Menstruation in girls and adolescents: Using the menstrual cycle as a vital sign. Paediatrics. 2006; 118 (5): 2245 - 2250.

[9]. Dambhare DG, Wagh SV \& Dudhe JY. Age at menarche and menstrual cycle pattern among school adolescent girls in Central India. Glob J Health Sci. 2012; 4 (1): 105 - 111.

[10]. Desalegn TZ, Berihum M \& Abay M. Age at menarche and the menstrual pattern of secondary school adolescents in Northwest Ethiopia. BMC Women Health. 2009; 9 (29): 1 - 8.

[11]. Kharde A, Reddy R, Phulambrikar R \& Jadhav J. A cross-sectional study on menstrual age and menstrual disorders. Int J Health Sci \& Res. 2016; 6(6): 19 - 23.

[12]. Karout N, Hawai SM \& Altuwaijri S. Prevalence and pattern of menstrual disorders among Lebanese Nursing students. East Mediterr Health J. 2012; 18 (4): 346 - 352.

[13]. Marianne E, McPherson ME \& Korfine L. Menstruation across time: menarche, menstrual attitudes, experiences and behaviours. Women's Health Issues. 2004; 14: 193 - 200.

[14]. Sulaymen HU, Ameh N, Adebiyi G et al. Age at menarche and prevalence of menstrual abnormalities among adolescents in Zaria, Northern Nigeria. Annals Nig Med. 2013; 7(2): 66 - 70. 
Texila International Journal of Public Health

Volume 4, Issue 4, Dec 2016

Table 1. Socio-demographic data of respondents

\begin{tabular}{|l|c|}
\hline VARIABLES & Frequency (\%) \\
\hline Age Group (years) & $26(4.9)$ \\
\hline 10 years & $56(10.7)$ \\
11 years & $54(10.3)$ \\
12 years & $70(13.3)$ \\
13 years & $88(16.7)$ \\
14 years & $78(14.8)$ \\
15 years & $88(16.7)$ \\
16 years & $30(5.7)$ \\
17 years & $26(4.9)$ \\
18 years & $10(1.9)$ \\
19 years \\
\hline Type of family & $380(72.2)$ \\
\hline Nuclear Family & $112(21.3)$ \\
Extended Family & $34(6.5)$ \\
No Response & $316(60.1)$ \\
\hline Religion & $210(39.9)$ \\
\hline Christianity \\
Islam & $206(39.2)$ \\
\hline Level of education & $268(51.0)$ \\
\hline Junior Secondary School & $44(8.3)$ \\
Senior Secondary School & $8(1.5)$ \\
Ordinary Level (O'Level) Degree \\
Undergraduate \\
\hline Position in family \\
\hline First Daughter \\
Middle Daughter & $292(55.5)$ \\
Last Daughter & $132(25.1)$ \\
Only Daughter & $72(13.7)$ \\
No Response & $28(5.3)$ \\
\hline Relationship with mother & $2(5.3)$ \\
\hline Very Close & $416(79.1)$ \\
Close & $86(16.3)$ \\
Ordinary Not Close & $10(1.9)$ \\
No Response & $4(0.8)$ \\
\hline
\end{tabular}

Table 2. Pre-menstrual training and menstrual hygiene practices

\begin{tabular}{|l|c|}
\hline VARIABLES & Frequency (\%) \\
\hline Current menstrual period absorbent/material disposal \\
\hline Water Closet & $116(22.1)$ \\
Dustbin & $100(19.0)$ \\
Burning & $84(16.0)$ \\
Pit Latrine & $50(9.5)$ \\
Washing (Cloth) & $32(6.1)$ \\
Farmland/Farm Location & $16(3.0)$ \\
Anywhere & $8(1.5)$ \\
No Response & $120(22.8)$ \\
\hline Age at menarche (first menstruation) in years \\
\hline 9 years & $12(2.3)$ \\
10 years & $36(6.8)$ \\
\hline
\end{tabular}




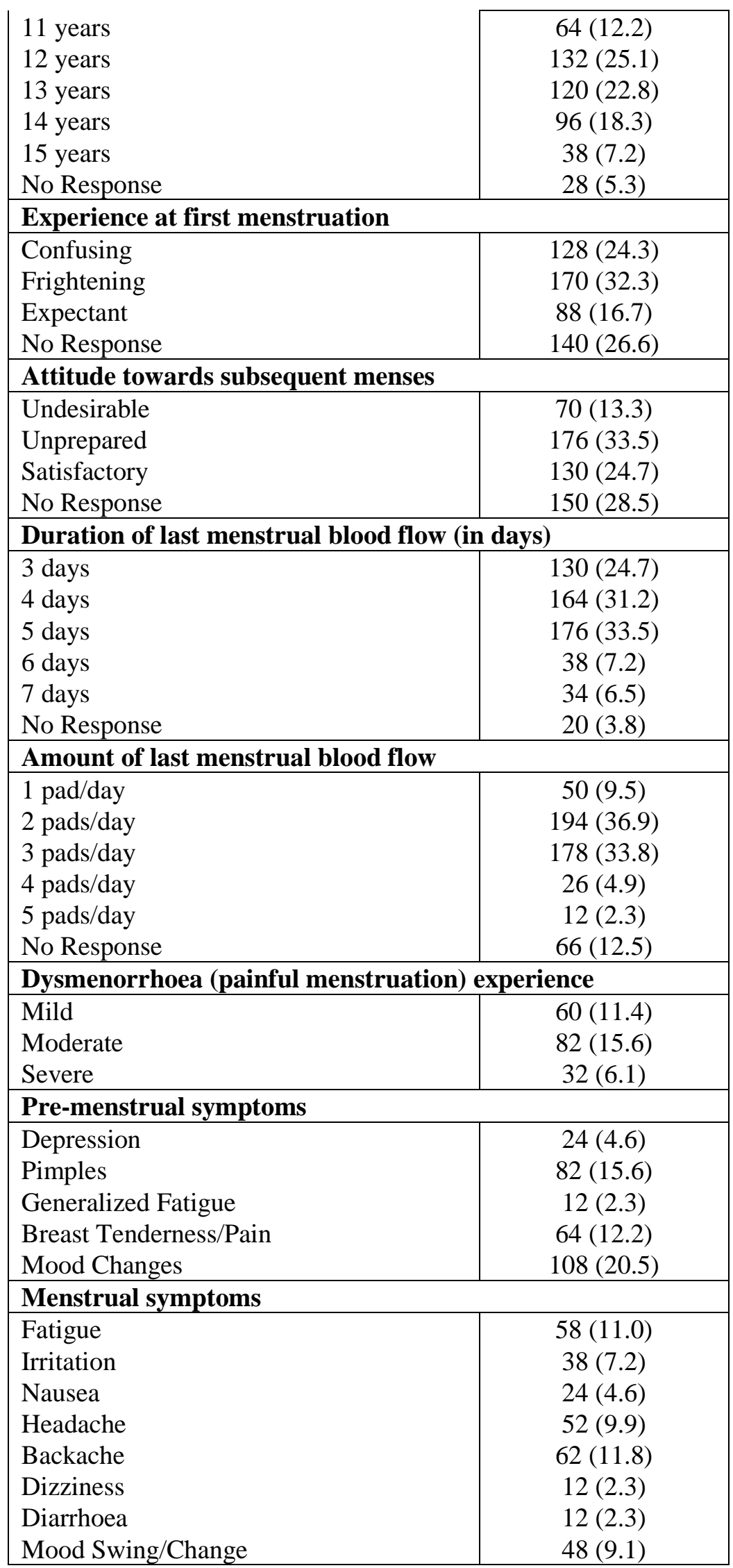


Texila International Journal of Public Health

Volume 4, Issue 4, Dec 2016

Table 3. Chi square result showing factors influencing pre-menstrual training and menstrual hygiene

\begin{tabular}{lllll} 
VARIABLES & $\boldsymbol{\chi}^{\mathbf{2}}$ & df & Critical value & Decision \\
\hline $\begin{array}{l}\text { Educational status on menstrual hygiene } \\
\text { practices }\end{array}$ & 16.158 & 12 & 21.03 & Accepted \\
$\begin{array}{l}\text { Relationship with mothers on pre- } \\
\text { menarcheal training }\end{array}$ & 12.210 & 8 & 15.51 & Accepted \\
$\begin{array}{l}\text { Educational attainment of mother on pre- } \\
\text { 25.408 }\end{array}$ & 14 & 23.69 & Rejected
\end{tabular}
menarcheal training

1) Educational status has no significant influence on menstrual hygiene practices

2) Relationship with mothers have no significant effect on pre-menarcheal training

3) Educational attainment of mother have no significant effect on pre-menarcheal training

The null hypothesis is rejected when the test statistic is greater than the tabled value or critical value. 